\title{
DIREITOS HUMANOS E AÇÕES AFIRMATIVAS NO DIREITO BRASILEIRO: CONTRIBUIÇÃO DA TEORIA LIBERAL DE JOHN RAWLS
}

\author{
Max Emiliano da Silva Sena ${ }^{1}$ \\ Liliane Lisboa de Oliveira Barbosa ${ }^{2}$
}

\section{RESUMO}

Este trabalho propõe-se a analisar a contribuição da teoria liberal de John Rawls para o embasamento teórico das ações afirmativas, enquanto medidas de promoção da igualdade material entre pessoas que não se encontram no mesmo patamar de oportunidades, com um olhar para o Direito brasileiro. Pelo princípio da diferença, admitem-se diferenciações entre as pessoas, desde que seja para beneficiar os menos favorecidos. $\mathrm{O}$ ordenamento jurídico brasileiro prevê medidas de ações afirmativas, em sintonia com a teoria dos direitos humanos. Utilizou-se o método de abordagem dedutivo e a pesquisa dogmático-jurídica de natureza bibliográfica, por meio da consulta de obras e documentos.

Palavras-chave: Direitos humanos; Ações afirmativas; Igualdade; Princípio da diferença de John Rawls; Constituição Federal de 1988.

\section{HUMAN RIGHTS AND AFFIRMATIVE ACTIONS IN BRAZILIAN LAW: CONTRIBUTION OF JOHN RAWLS'S LIBERAL THEORY}

\begin{abstract}
This paper proposes to analyze the contribution of John Rawls' liberal theory to the theoretical basis of affirmative actions, as measures to promote material equality between people who are not at the same level of opportunity, with a look at Brazilian law. By the principle of difference, differences between people are allowed, provided that it is to benefit the less favored. The Brazilian legal system provides affirmative action measures, in line with human rights theory. The method of deductive approach and the dogmatic-juridical research of bibliographical nature were used, through the consultation of works and documents.
\end{abstract}

Keywords: Human rights; Affirmative actions; Equality; Principle of the difference of John Rawls; Federal Constitution of 1988.

\section{INTRODUÇÃO}

O sistema global de proteção dos direitos humanos inspirou fortemente o Estado brasileiro, instituído pela Constituição Federal de 1988, que se estrutura em princípios que

\footnotetext{
${ }^{1}$ Procurador do Trabalho, do Ministério Público do Trabalho (MPT). Mestrando em Direito pela Universidade FUMEC. Especialista em Direito Público pela Faculdade de Direito do Vale do Rio Doce (FADIVALE) e em Direitos Humanos e Trabalho pela Escola Superior do Ministério Público da União (ESMPU). Professor Universitário.

${ }^{2}$ Advogada. Especialista em Direito do Trabalho e Direito Processual do Trabalho pela Faculdade de Direito do Vale do Rio Doce (FADIVALE).
} 
perfilham a dignidade da pessoa humana, a liberdade e a igualdade como valores supremos e reitores de todo o arcabouço normativo nacional e das ações governamentais, além de impor limites às relações privadas, por força das eficácias vertical e horizontal dos direitos fundamentais.

A busca pela concretização da igualdade substancial recebeu tratamento especial do Constituinte de 1988, o que deflui dos objetivos propostos para a República brasileira, que se pautam basicamente na promoção da liberdade e da igualdade substancial e na vedação da discriminação negativa e exclusiva, bem como do extenso rol de direitos sociais garantidos e que permeiam todo o texto constitucional. Nesse cenário, ganha relevo a adoção das ações afirmativas, compreendidas como mecanismos para a aceleração do processo de concreção da igualdade material.

Considerando que o pensamento liberal, também inspirador da Constituição brasileira, encontra nos direitos civis e nas liberdades públicas a sua principal ênfase, o presente trabalho propõe-se pesquisar resposta ao tema problema, consistente na indagação acerca de qual seria a contribuição do pensamento liberal para a promoção das ações afirmativas, especificamente na perspectiva da teoria do filósofo John Rawls, fundada nos princípios de justiça e de equidade, tão caros na construção dos direitos humanos, enquanto fundamentos e fins de sua essência.

O marco teórico adotado repousa no princípio da diferença, formulado por John Rawls, cuja aplicabilidade ao embasamento teórico das ações afirmativas será objeto de investigação, como forma de se aferir se há espaço no pensamento liberal para a fundamentação da igualdade material, em que pese a ênfase conferida aos direitos de liberdade.

O estudo principia-se com a visitação do processo histórico de construção dos direitos de liberdade (direitos contra o Estado) e de igualdade (direitos sociais, por meio do Estado). Após, o foco volta-se para os princípios da dignidade da pessoa humana e da igualdade no ordenamento jurídico brasileiro. Em seguida, propõe-se a análise da teoria de John Rawls, com destaque para o princípio da diferença, a fim de se investigar eventuais contribuições para o embasamento teórico das ações afirmativas. Serão perfunctoriamente vistas algumas espécies de ações afirmativas acolhidas pelo Direito brasileiro, tanto em suas vertentes repressivas quanto promocionais, com posterior encaminhamento à conclusão do trabalho. 


\title{
DIREITOS HUMANOS E AÇÕES AFIRMATIVAS NO DIREITO BRASILEIRO: CONTRIBUIÇÃO DA TEORIA LIBERAL DE JOHN RAWLS
}

Para o alcance dos objetivos propostos neste trabalho, utilizou-se o método de abordagem dedutivo e a pesquisa dogmático-jurídica de natureza bibliográfica, por meio da consulta de obras e documentos.

\section{OS DIREITOS HUMANOS CONTRA O ESTADO}

Os regimes absolutistas desconheciam limites à atuação dos soberanos, detentores que eram de poder incontrastável no âmbito do território do seu reinado. Os indivíduos que não integravam o clero ou a nobreza não possuíam direitos contra o poder real, sendo considerados meros objetos de direito.

Foi contra esse tipo de estrutura de poder que se levantou o movimento revolucionário francês de 1789, de matriz liberal-burguesa, com o objetivo de dar fim ao antigo regime absolutista e garantir o exercício das liberdades públicas e dos direitos políticos.

Na dicção de Pedro Lenza, esses direitos contra o Estado, também chamado de direitos de primeira dimensão, "marcam a passagem de um Estado autoritário para um Estado de Direito e, nesse contexto, o respeito às liberdades individuais, em uma verdadeira perspectiva de absenteísmo estatal" (LENZA, 2014, p. 1056).

No mesmo sentido, André de Carvalho Ramos aduz:

\begin{abstract}
A primeira geração engloba os chamados direitos de liberdade, que são direitos às prestações negativas, nas quais o Estado deve proteger a esfera de autonomia do indivíduo. São denominados também "direitos de defesa", pois protegem o indivíduo contra intervenções indevidas do Estado, possuindo caráter de distribuição de competências (limitação) entre o Estado e o ser humano. Por regrar a atuação do indivíduo, delimitando o seu espaço de liberdade e, ao mesmo tempo, estruturando o modo de organização do Estado e do seu poder, são os direitos de primeira geração compostos pelos direitos civis e políticos. Por isso, são conhecidos como direitos (ou liberdades) individuais, tendo como marco as revoluções liberais do século XVIII na Europa e Estados Unidos. Essas revoluções visavam restringir o poder absoluto do monarca, impingindo limites à ação estatal (RAMOS, 2015, p. 55-56).
\end{abstract}

A Magna Carta de 1215, do rei João Sem Terra, o Bill of Rights, de 1688, a Declaração Americana de Direitos, de 1776, e a Declaração Francesa dos Direitos do Homem e do Cidadão, de 1789, são alguns documentos que bem representam essa importante fase de direitos plasmados contra o Estado, com o objetivo de proteger o indivíduo contra o poder ilimitado dos governantes (LENZA, 2014).

O Estado de Direito, fruto da concepção que marca esse período, traduz um Estado submetido e jungido às normas por ele mesmo editadas, ou seja, os governantes não mais 
dispunham de poder incontrastável, devendo respeitar e observar os limites impostos pela Constituição e pelas leis, tudo com o claro escopo de salvaguardar os direitos individuais.

Nota-se, dessa forma, que o conceito de Estado de Direito vincula-se à garantia dos direitos individuais contra o Estado. Nesse sentido, Jacques Chevallier destaca:

\begin{abstract}
O primeiro aspecto da limitação do poder reside na referência aos direitos do homem. O Estado de Direito implica, com efeito, certa concepção das relações entre o indivíduo e o Estado, que sustenta todo o edifício jurídico: não somente o poder do Estado encontra os seus limites nos direitos fundamentais reconhecidos aos indivíduos, o que cria, assim, a possibilidade de uma "oposição ao poder fundada no direito" (C. Lefort), mas também ela tem por finalidade, por justificação última, a garantia desses direitos; no final das contas, o Estado de Direito se apoia na afirmação da primazia do indivíduo na organização social e política, o que acarreta ao mesmo tempo a instrumentalização do Estado, cujo objetivo é servir às liberdades e à subjetivização do direito (L. Ferry, A. Renaut, Philosophie politique, III Des droits de l'homme à l'idée républicaine, PUF, 1985), que dota cada um de um estatuto, que lhe atribui um poder de exigibilidade e lhe confere uma capacidade de ação (CHEVALLIER, 2013, p. 46).
\end{abstract}

Os direitos humanos, a partir dessa análise, consubstanciam direitos de oposição contra os abusos estatais, ou seja, direitos de resistência contra a opressão. Integram esses direitos, por exemplo, a igualdade de todos perante a lei, não se tolerando mais tratamentos desiguais para pessoas que estejam numa mesma situação jurídica, como ocorria sob a égide do ancien régime.

Nesse sentido, Costas Douzinas consigna que:

[...], é possível argumentar que a Declaração de Direitos Humanos é a precondição da soberania e está inescapavelmente entrelaçada com a legislação. O soberano moderno chega à sua vida onipotente ao proclamar os direitos dos cidadãos. Vistos a partir desta perspectiva, os direitos humanos são tentativas de construir um princípio protetor contra o Leviatã, com base no reconhecimento do desejo e na instituição como um contraprincípio ao desejo do desejo do Estado" (DOUZINAS, 2009, p. 119).

Portanto, os direitos contra o Estado são direitos de resistência, por meio da imposição de um não fazer (absenteísmo estatal), como forma de garantir o direito de ir e vir, a igualdade formal de todos perante a lei, o direito de propriedade, a inviolabilidade de domicílio, os sigilos bancário e telefônico e a liberdade de expressão, entre outros que traduzem o valor liberdade.

\title{
3 OS DIREITOS HUMANOS POR MEIO DO ESTADO
}




\title{
DIREITOS HUMANOS E AÇÕES AFIRMATIVAS NO DIREITO BRASILEIRO: CONTRIBUIÇÃO DA TEORIA LIBERAL DE JOHN RAWLS
}

A previsão de direitos contra o Estado, mediante a instituição de um Estado submetido ao Direito, representou historicamente um grande avanço em termos de proteção dos direitos humanos, na medida em que o indivíduo passa a ser detentor de direitos contra o Estado, acionáveis perante o Poder Judiciário, em caso de inobservância e violação.

Como visto, uma das garantias decorrente dessa conquista foi a igualdade de todos perante a lei, tanto que já no artigo $1^{\circ}$, da Declaração Francesa dos Direitos do Homem e do Cidadão, de 1789, proclamou-se que: "Os homens nascem e são livres e iguais em direitos. As distinções sociais só podem fundamentar-se na utilidade comum” (FRANÇA, 1789).

Não obstante tenha representado historicamente expressiva conquista em termos de proteção dos direitos humanos por meio de mecanismos de salvaguarda contra os abusos estatais, os direitos contra o Estado não lograram alcançar a completude das necessidades humanas.

A importância desses direitos contra o Estado é destacada por Flávia Piovesan, no sentido de que:

\begin{abstract}
Diante do absolutismo, fazia-se necessário evitar os excessos, o abuso e o arbítrio do poder. Nesse sentido, os direitos humanos surgem como reação e resposta aos excessos do regime absolutista, na tentativa de impor controle e limites à abusiva atuação do Estado. A solução era limitar e controlar o poder do Estado, que deveria pautar-se pela legalidade e respeitar os direitos fundamentais. A não atuação estatal significava liberdade. Daí o primado do valor liberdade, com a supremacia dos direitos civis e políticos e a ausência de previsão de qualquer direito econômico, social e cultural (PIOVESAN, 2014, p. 311-312).
\end{abstract}

Diante dessa lacuna na garantia de direitos sociais, num palco histórico de péssimas condições de trabalho, durante a Revolução Industrial europeia, a partir do século XIX eclodem movimentos de reivindicação de melhorias nas condições de trabalho e de previsão de normas de assistência aos necessitados, ante a constatação de que os direitos de proteção contra a prática de arbitrariedades estatais não foram capazes de alterar a realidade fática de pobreza e de vulnerabilidade de considerável parte da população. A igualdade meramente formal não refletiu na conquista da igualdade material.

Na dicção de Pedro Lenza,

O início do século XX é marcado pela Primeira Grande Guerra e pela fixação de direitos sociais. Essa perspectiva de evidenciação dos direitos sociais, culturais, econômicos, bem como dos direitos coletivos, ou de coletividade, correspondendo aos direitos de igualdade (substancial, real e material, e não meramente formal), mostra-se marcante em alguns documentos, destacando-se: - Constituição do México, de 1917; - Constituição de Weimar, de 1919, na Alemanha, conhecida como a Constituição da primeira república alemã; - Tratado de Versalhes, 1919 (OIT); - no Brasil, a Constituição de 1934 [...] (LENZA, 2014, p. 1057). 
Além da imprescindível igualdade formal, de todos perante a lei, percebeu-se que, diante do estado de miserabilidade e de hipossuficiência de parcela considerável da sociedade, avultava também a necessidade de se promover a igualdade material ou substancial, levandose em consideração o estado fático, a vida real das pessoas.

A respeito dessa fase, André de Carvalho Ramos aduz:

\begin{abstract}
A segunda geração de direitos humanos representa a modificação do papel do Estado, exigindo-lhe um vigoroso papel ativo, além do mero fiscal das regras jurídicas. Esse papel ativo, embora indispensável para proteger os direitos de primeira geração, era visto anteriormente com desconfiança, por ser considerado uma ameaça aos direitos dos indivíduos. Contudo, sob a influência das doutrinas socialistas, constatou-se que a inserção formal da liberdade e igualdade em declarações de direitos não garantiam a sua efetiva concretização, o que gerou movimentos sociais de reivindicação de um papel ativo do Estado para assegurar uma condição material mínima de sobrevivência. Os direitos sociais são também titularizados pelo indivíduo e oponíveis ao Estado. São reconhecidos o direito à saúde, educação, previdência social, habitação, entre outros, que demandam prestações positivas do Estado para seu atendimento e são denominados direitos de igualdade por garantirem, justamente às camadas mais miseráveis da sociedade, a concretização das liberdades abstratas reconhecidas nas primeiras declarações de direitos (RAMOS, 2015, p. 56).
\end{abstract}

No sistema global de proteção dos direitos humanos, tem-se que a Declaração Universal dos Direitos Humanos, da Organização das Nações Unidas (ONU), proclama em seu texto tanto direitos de primeira quanto de segunda dimensões, os quais têm como destinatário o ser humano enquanto sujeito de direitos no plano internacional (ORGANIZAÇÃO, 1948). No entanto, em razão das discussões acerca da natureza obrigatória ou não da Declaração Universal dos Direitos Humanos, foram editados no âmbito da ONU, em 1966, dois documentos revestidos de inegável natureza obrigatória: o Pacto Internacional sobre Direitos Civis e Políticos, que prevê direitos de primeira dimensão, e o Pacto Internacional sobre Direitos Econômicos, Sociais e Culturais, com a previsão de direitos de segunda dimensão (ORGANIZAÇÃO, 1966).

Para Sidney Guerra,

[...] os direitos sociais seriam aqueles necessários à participação plena na vida da sociedade, incluindo o direito à educação, a instituir e manter a família, à proteção à maternidade e à infância, ao lazer e à saúde etc. Os direitos econômicos destinam-se a garantir um padrão mínimo de vida e segurança material, de modo que cada pessoa desenvolva suas potencialidades. Os direitos culturais dizem respeito ao regaste, estímulo e preservação das formas de reprodução cultural das comunidades, bem como à participação de todos nas riquezas espirituais comunitárias (GUERRA, 2015, p. 68). 
Por seu turno, José Afonso da Silva confere o seguinte conceito aos direitos sociais:

[...] os direitos sociais, como dimensão dos direitos fundamentais do homem, são prestações positivas proporcionadas pelo Estado direta ou indiretamente, enunciadas em normas constitucionais, que possibilitam melhores condições de vida aos mais fracos, direitos que tendem a realizar a igualização de situações sociais desiguais. São, portanto, direitos que se ligam ao direito de igualdade. Valem como pressupostos do gozo dos direitos individuais na medida em que criam condições materiais mais propícias ao auferimento da igualdade real, o que, por sua vez, proporciona condição mais compatível com o exercício efetiva da liberdade (SILVA, 2008, p. 286-287).

Assim, resta claro que os direitos sociais demandam conduta positiva do Estado, no sentido serem oferecidas prestações materiais necessárias para a melhoria das condições de vida dos hipossuficientes, razão pela qual não traduz tecnicamente direitos contra o Estado em sua acepção de conduta absenteísta, mas sim direitos por meio do Estado, uma vez que reclamam deste uma atuação positiva e proativa para a sua concretização.

\section{A DIGNIDADE DA PESSOA HUMANA E A IGUALDADE NO ORDENAMENTO JURÍDICO BRASILEIRO}

A Constituição Federal de 1988 (CF/88), em harmonia com o sistema global de proteção dos direitos humanos, fundado no respeito à dignidade da pessoa humana, adotou postura de centralidade da pessoa humana, conferindo-lhe destaque e relevância maior em todo o sistema jurídico.

Principiando pelo preâmbulo, assentou-se que o Estado Democrático instituído pela nova Constituição destina-se a assegurar o exercício dos direitos sociais e individuais, a igualdade e a justiça, entre outros objetivos (BRASIL, 1988).

Adentrando no texto constitucional, tem-se que no artigo $1^{\circ}$ a dignidade da pessoa humana foi alçada à condição de fundamento do Estado Democrático de Direito instituído na República Federativa do Brasil, do que ressai a adoção da centralidade humana na nova ordem estabelecida ${ }^{3}$.

3 Constituição Federal de 1988: “Art. 1 A República Federativa do Brasil, formada pela união indissolúvel dos Estados e Municípios e do Distrito Federal, constitui-se em Estado Democrático de Direito e tem como fundamentos: I - a soberania; II - a cidadania; III - a dignidade da pessoa humana; IV - os valores sociais do trabalho e da livre iniciativa; V - o pluralismo político". 
Da leitura da Constituição brasileira é possível perceber que a dignidade da pessoa humana permeia todo texto, condicionando e direcionando todo o sistema.

A propósito, pertinentes as ponderações de Max Emiliano da Silva Sena, sentido de que:

Ao erigir a dignidade da pessoa humana à condição de fundamento do Estado Democrático de Direito, a Constituição Federal de 1988 diz de forma firme, segura e eloquente que no Estado brasileiro a pessoa humana desfruta de especial destaque, sendo o centro de todo o sistema, de molde que todo o ordenamento jurídico, todos os órgãos de governo, todas as ações políticas e todas as condutas particulares devem respeito à pessoa humana (SENA, 2016).

André de Carvalho Ramos faz sucinta análise da presença da dignidade da pessoa humana pelo texto constitucional:

A Constituição de 1988 estabelece que um dos fundamentos do Estado Democrático de Direito é a "dignidade da pessoa humana" (art. $1^{\circ}$, III). Além disso, o texto constitucional brasileiro afirma que toda ação econômica tem como finalidade assegurar a todos existência digna (art. 170). Por sua vez, no art. $226, \$ 7^{\circ}$, ficou determinado que o planejamento familiar é livre decisão do casal fundado no princípio da dignidade da pessoa humana. Já o art. 227 determina que cabe à família, à sociedade e ao Estado assegurar a dignidade à criança, ao adolescente e ao jovem. No art. 230, a Constituição de 1988 prevê que a família, a sociedade e o Estado têm o dever de amparar as pessoas idosas, defendendo sua dignidade e bem-estar (RAMOS, 2015, p. 73).

Vale consignar que a dignidade da pessoa humana não se trata de mera previsão simbólica na Constituição brasileira, antes, pelo contrário, possui eficácia vinculante em face de todo o sistema e, como norma jurídica impositiva, pode ser invocada e aplicada para a solução de casos concretos.

Há dois elementos que caracterizam a dignidade da pessoa humana, que acabam por desempenhar desdobramento de suas principais funções: a) o elemento negativo, consistente na vedação de todo o tipo de tratamento excludente, degradante e odioso contra a pessoa humana; e b) o elemento positivo, traduzido na conduta proativa e promocional, com o objetivo de garantir condições materiais mínimas para uma existência digna da pessoa humana (RAMOS, 2015).

A partir dessas duas vertentes (negativa e positiva), Ingo Wolfgang Sarlet propõe a seguinte conceituação jurídica para a dignidade da pessoa humana:

Temos por dignidade da pessoa humana a qualidade intrínseca e distintiva de cada ser humano que o faz merecedor do mesmo respeito e consideração por parte do Estado e da comunidade, implicando, neste sentido, um completo de direitos e deveres fundamentais que assegurem a pessoa tanto contra todo e qualquer ato de cunho degradante e desumano, como venham a lhe garantir as condições existenciais mínimas para uma vida saudável, além de propiciar e promover sua participação 


\section{DIREITOS HUMANOS E AÇÕES AFIRMATIVAS NO DIREITO BRASILEIRO: CONTRIBUIÇÃO DA TEORIA LIBERAL DE JOHN RAWLS}

ativa correspondente nos destinos da própria existência e da vida em comunhão dos demais seres humanos" (SARLET, 2001, p. 60).

De acordo com André de Carvalho Ramos, "há aqueles que defendem que o núcleo essencial do princípio da dignidade da pessoa humana é composto pelo mínimo existencial, que consiste em um conjunto de prestações mínimas sem as quais se poderá afirmar que o indivíduo se encontra em situação de indignidade" (RAMOS, 2015, p. 75).

A propósito do cesto de direitos que integram o denominado mínimo existencial ou patamar mínimo civilizatório, Ana Paula de Barcellos consigna:

\footnotetext{
Na linha do que se identificou no exame sistemático da própria Carta de 1988, o mínimo existencial que ora se concebe é composto de quatro elementos, três materiais e um instrumental, a saber: a educação básica (assumindo-se a nova nomenclatura constitucional), a saúde básica, a assistência aos desamparados e o acesso à Justiça (BARCELLOS, 2011, p. 302).
}

Contribuindo com a discussão da temática, Maria Celina Bodin de Moraes defende que o conteúdo da dignidade da pessoa humana é composto por quatro princípios básicos: o da igualdade, integridade física e psíquica, liberdade e solidariedade (MORAES, 2003).

A dignidade da pessoa humana é passível de manejo no sistema jurídico, para o exercício de funções de imposição de limites à atuação estatal e dos particulares (eficácias vertical e horizontal), de promoção dos direitos fundamentais, de condicionamentos à atuação do intérprete, de conferência de unidade à Constituição e ao ordenamento jurídico como um todo, e de promoção da igualdade entre as pessoas, apenas para citar algumas.

No que tange à promoção da igualdade, pertinente trazer à colação o pensamento filosófico de Immanuel Kant, que se revelou de grande importância para a construção e a fundamentação da dignidade da pessoa humana.

Segundo Immanuel Kant, "no reino dos fins, tudo tem um preço ou uma dignidade. Quando uma coisa tem preço, pode ser substituída por algo equivalente; por outro lado, a coisa que se acha acima de todo o preço, e por isso não admite qualquer equivalência, compreende uma dignidade" (KANT, 2011, p. 65).

A filosofia de Kant insurge-se contra o utilitarismo banal do ser humano, ou da coisificação do homem, como forma se atingir objetivos por outrem, defendendo que o homem existe como um fim em si mesmo.

Nesse sentido, destaca Immanuel Kant:

Agora eu afirmo: o homem - e, de uma maneira geral, todo o ser racional - existe como um fim em si mesmo, em não apenas como meio para uso arbitrário desta ou 
daquela vontade. Em todas as suas ações, pelo contrário, tanto nas direcionadas a ele mesmo como nas que o são a outros seres racionais, deve ser ele sempre considerado simultaneamente como fim. [...] o homem não é uma coisa; não é, portanto, um objeto passível de ser utilizado como simples meio, mas, pelo contrário, deve ser considerado sempre em todas as suas ações como fim em sim mesmo" (KANT, 2011 , p. 58 e 60).

Dessa forma, vistas a partir do valor essencial que lhes confere direitos, qual seja, a dignidade inerente a todo o ser humano, as pessoas devem ser tratadas com igualdade, sendo descabido todo o tipo de discriminação odiosa e vedada pelo ordenamento.

A Constituição brasileira, em seu artigo $5^{\circ}$, caput, estabelece que "todos são iguais perante a lei, sem distinção de qualquer natureza, garantindo-se aos brasileiros e aos estrangeiros residentes no País a inviolabilidade do direito à vida, à liberdade, à igualdade, à segurança e à propriedade" (BRASIL, 1988).

Além disso, como meta estabelecida para o Estado instituído, a CF/88 prevê no artigo $3^{\text {o }}$ que constituem objetivos da República Federativa do Brasil: "erradicar a pobreza e a marginalização e reduzir as desigualdades sociais e regionais" (inciso III), e " promover o bem de todos, sem preconceitos de origem, raça, sexo, cor, idade e quaisquer outras formas de discriminação", do que se extrai o compromisso com a promoção da igualdade e a vedação de toda a forma de diferenciação e exclusão abusiva (BRASIL, 1988).

Como formas mais concretas de garantia da igualdade, a Constituição Federal de 1988, prevê no artigo $5^{\circ}$ que: homens e mulheres são iguais em direitos e obrigações, nos termos da Constituição (inciso I); a lei punirá qualquer discriminação atentatória dos direitos e liberdades fundamentais (inciso XLI); e que a prática do racismo constitui crime inafiançável e imprescritível, sujeito à pena de reclusão, nos termos da lei (inciso XLII) (BRASIL, 1988).

Os direitos sociais, por seu turno, previstos nos artigos $6^{\circ}$ a 11 , da $\mathrm{CF} / 88$, objetivam assegeurar direitos básicos e condições de exercício e defesa desses direitos pelos trabalhadores, o que de certa forma atende à promoção da igualdade substancial.

Em relação a esses direitos sociais, vale destacar em especial que o art. $7^{\circ}$ da $C F / 88$ prevê a proibição de diferença de salários, de exercício de funções e de critério de admissão por motivo de sexo, idade, cor ou estado civil (inciso XXX) e a proibição de qualquer discriminação no tocante a salário e critério de admissão do trabalhador com deficiência (inciso XXXI) (BRASIL, 1988). 
O ordenamento jurídico brasileiro, portanto, encontra-se fundado nos valores da dignidade da pessoa humana, da igualdade e da liberdade, todos albergados pela Constituição de 1988.

\section{CONTRIBUIÇÃO DA TEORIA DE RAWLS PARA AS AÇÕES AFIRMATIVAS}

As ações afirmativas possuem como fim e fundamento o princípio da igualdade, podendo ser compreendidas como medidas compensatórias que possuem como objetivo proporcionar a concretização da igualdade substancial entre pessoas que não se encontram no mesmo patamar em termos de oportunidades.

Flávia Piovesan refere-se às ações afirmativas como poderoso instrumento de inclusão social, na medida em que traduzem "medidas especiais e temporárias que, buscando remediar um passado discriminatório, objetivam acelerar o processo de igualdade, com o alcance da igualdade substantiva por parte de grupos vulneráveis, como as minorias étnicas e raciais, as mulheres, dentre outros grupos" (PIOVESAN, 2008, p. 237).

Por seu turno, Michael J. Sandel, aduz que "o argumento compensatório considera a ação afirmativa uma solução para remediar as injustiças do passado" (SANDEL, 2016, p. 212).

Alguns vislumbram nas ações afirmativas medidas para o alcance da justiça social, por meio da oferta de impulsos ou incentivos em favor de pessoas ou grupos menos favorecidos, do que se infere que tais ações encerram em si esse ideal de justiça, tão caro quando se fala em direitos humanos.

Nesse sentido, a teoria do filósofo John Rawls plasma uma estrutura básica da sociedade construída por pessoas livres e autônomas que, na "posição original ou inicial", atuam sob o "véu da ignorância", ou seja, não levam em consideração atributos que de alguma forma sejam capazes de estabelecer diferenciações com base em critérios diversos, tais como sexo, inteligência, fortuna, condição social, entre outros, de molde que a estrutura e a organização sociais pautem-se segundo princípios de justiça e de equidade.

John Rawls, formula dois princípios de justiça, da seguinte forma:

Primeiro: cada pessoa deve ter um direito igual ao sistema mais extenso de iguais liberdades fundamentais que seja compatível com um sistema similar de liberdades para as outras pessoas. Segundo: as desigualdades sociais e económicas devem estar dispostas de tal modo que tanto (a) se possa razoavelmente esperar que se estabeleçam em benefício de todos como (b) estejam vinculadas a cargos e posições acessíveis a todos" (RAWLS, 2008, p. 73). 
Para Rawls, o primeiro princípio (igualdade de oportunidades) possui prioridade em relação ao segundo (princípio da diferença), de molde que, segundo teoriza, não se deve renunciar nenhuma das liberdades básicas em favor de uma distribuição mais equitativa de cargos e poderes que convirja para uma igualdade material das condições socioeconômicas, sendo perceptível que "se o primeiro princípio de justiça aponta o conjunto de liberdades e direitos tradicionais (civis e políticos), o segundo relaciona-se aos direitos sociais e econômicos" (GUERRA, 2015, p. 88).

Na formulação dos princípios de justiça, há uma proeminência da igualdade formal, ligada aos direitos de primeira dimensão, seguindo-se a linha de raciocínio de que "se acharmos que a justiça sempre expressa algum tipo de igualdade, então a justiça formal requer que, em sua administração, as leis e as instituições se apliquem com igualdade" (RAWLS, 2008, p. 70).

Nesse diapasão, o entendimento rawlsiano pauta-se na ideia de que "onde encontramos a justiça formal, o Estado de Direito e o respeito às expectativas legítimas, é provável que também encontremos a justiça substantiva” (RAWLS, 2008. p. 72).

Em princípio, essas formulações de cunho liberal não atenderiam às políticas inclusivas promovidas pelas ações afirmativas, diante da proeminência das liberdades públicas e de justiça formal nem sempre associada à justiça substancial e verificável no campo pragmático.

No entanto, avançando em sua teoria, John Rawls defende ser impossível garantir oportunidades iguais de realização para as pessoas que têm aptidões semelhantes, uma vez que aptidões naturais se desenvolvem e amadurecem a partir de influências e circunstancias sociais e familiares, concluindo que "o fato de que a concepção liberal fracassa nesse ponto nos incentiva a procurar outra interpretação dos dois princípios da justiça” (RAWLS, 2008, p. 89).

Diante dessa constatação, Jonh Rawls formula o princípio da diferença:

O princípio da diferença é, então, uma concepção fortemente igualitária no sentido de que, se não houver uma distribuição que melhore a situação de ambas as pessoas (limitando-nos ao caso de duas pessoas, para simplificar), deve-se preferir a distribuição igualitária. [...] Por mais que a situação de uma das pessoas melhore, do ponto de vista do princípio da diferença não há ganho algum, a não se que a outra pessoa também ganhe" (RAWLS, 2008, p. 91). 


\section{DIREITOS HUMANOS E AÇÕES AFIRMATIVAS NO DIREITO BRASILEIRO: CONTRIBUIÇÃO DA TEORIA LIBERAL DE JOHN RAWLS}

Como regra, portanto, as liberdades públicas (direitos civis e políticos), ou a igualdade de oportunidades, possuem preferência na teoria de John Rawls, sendo possível, no entanto, amainar o rigor da igualdade formal para que se logre melhorar a condição do hipossuficiente.

Com efeito, segundo Rawls, "se uma vantagem tiver como resultado a elevação das expectativas da posição mais desfavorecida, elevará as expectativas de todas as posições intermediárias” (RAWLS, 2008, p. 97).

A esse respeito, Sidney Guerra arremata:

Rawls assevera que as desigualdades existentes em uma sociedade podem ser justificadas na medida em que trazem vantagens para todos. Cabe recordar também que a igualdade de oportunidades tem prioridade sobre o princípio da diferença, ou seja, que os cargos e postos abertos a todos não podem sofrer limitações em compensação da aplicação de direitos que buscam maior igualdade de condições socioeconômicas (GUERRA, 2015, p. 88).

Esses dois princípios, da igualdade de oportunidades e da diferença, são passíveis de aplicação ao estudo das ações afirmativas, havendo importante contribuição do pensamento de Rawls para o seu embasamento teórico.

As ações afirmativas, é importante ressaltar, traduzem tratamento discriminatório e diferente em favor de pessoas ou grupos determinados, mas com o objetivo de inclusão e não de exclusão, razão qual são chamadas de discriminações positivas.

O tratamento desigual, no caso, funda-se na necessidade de se promover o equilíbrio e uma autêntica igualdade de oportunidades entre pessoas que não se encontram no mesmo patamar.

Boaventura de Souza Santos, citado por Flávia Piovesan, registra que:

Temos o direito a ser iguais quando a nossa diferença nos inferioriza; e temos o direito a ser diferentes quando a nossa igualdade nos descaracteriza. Daí a necessidade de uma igualdade que reconheça as diferenças e de uma diferença que não produza, alimente ou reproduza as desigualdades" (SANTOS apud PIOVESAN, 2008 p. 236).

As políticas compensatórias instrumentalizadoras das ações afirmativas são adotadas com a finalidade de aliviar os efeitos de um passado discriminatórios, bem como de promover a diversidade e a pluralidade social (PIOVESAN, 2008).

Essas ações devem ser compreendidas sob o viés de quem é incluído por meio delas, bem como do grupo social que recebe essa inclusão. No primeiro caso, ou seja, da pessoa favorecida, tem-se a concretização dos direitos à inclusão e à igualdade de oportunidade, com 
a aspiração de alcance da igualdade substancial. No segundo caso, do grupo que recebe a pessoa, vê-se garantido o direito à diversidade e à pluralidade.

A propósito, analisando o caso de inclusão de universitários, Michael J. Sandel registra com propriedade que "o princípio da diversidade se justifica em nome do bem comum - o bem comum da própria faculdade e também da sociedade em geral" (SANDEL, 2016, p. 213).

Essas duas formas de leitura da promoção das ações afirmativas encontram-se assento constitucional, a teor do que constam dos artigos $1^{\circ}$, III e V, $3^{\circ}$, I, III e IV, e $5^{\circ}$, todos da Constituição Federal de $1988^{4}$.

Do princípio da diferença de John Rawls pode ser extraída a viabilidade de serem estabelecidas diferenciações, com a eventual quebra do rigor da igualdade formal, desde que seja com a finalidade de favorecer aqueles considerados menos favorecidos, o que oferece importantes subsídios para o embasamento teórico das ações afirmativas.

As pessoas integrantes dos chamados grupos vulneráveis ou minoritários (não no sentido quantitativo, mas de aptidão para o efetivo usufruto de direitos), por meio das ações afirmativas, têm direito a uma inserção social, com base no princípio da dignidade da pessoa humana e nos ideais de justiça social, cuja compreensão se faz como meio de concretização da igualdade material.

Na perspectiva do grupo que recebe a pessoa titular do direito à inserção, tem-se a efetivação do direito à diversidade ou à pluralidade, seja na escola, na empresa ou no serviço público. Nessa linha, Luciana Dayoub Ranieri de Almeida registra: “[...] como corolário desse respeito à diversidade, cumprem as ações afirmativas importante papel de implantar uma maior representatividade dos grupos minoritários nos mais diversos domínios de atividade pública e privada" (ALMEIDA, 2011, p. 65).

\footnotetext{
${ }^{4}$ Constituição Federal de 1988: “Art. $1^{\circ}$ A República Federativa do Brasil, formada pela união indissolúvel dos Estados e Municípios e do Distrito Federal, constitui-se em Estado Democrático de Direito e tem como fundamentos:

[...] III - a dignidade da pessoa humana; V - o pluralismo político".

“Art. $3^{\circ}$ Constituem objetivos fundamentais da República Federativa do Brasil:

I - construir uma sociedade livre, justa e solidária; [...] III - erradicar a pobreza e a marginalização e reduzir as desigualdades sociais e regionais; IV - promover o bem de todos, sem preconceitos de origem, raça, sexo, cor, idade e quaisquer outras formas de discriminação".

"Art. $5^{\circ}$ Todos são iguais perante a lei, sem distinção de qualquer natureza, garantindo-se aos brasileiros e aos estrangeiros residentes no País a inviolabilidade do direito à vida, à liberdade, à igualdade, à segurança e à propriedade $[\ldots] "$.
} 


\section{DIREITOS HUMANOS E AÇÕES AFIRMATIVAS NO DIREITO BRASILEIRO: CONTRIBUIÇÃO DA TEORIA LIBERAL DE JOHN RAWLS}

No primeiro caso, o direito à inserção, garantido a um grupo, materializa-se no âmbito da individualidade de quem é inserido. Já na segunda compreensão, tem-se o direito à diversidade do grupamento social que recebe a pessoa incluída, de molde que há um ponto de convergência ou de interconexão entre as duas formas de leitura dos mecanismos de ações afirmativas, com benefícios individuais e também para a sociedade como um todo, em harmonia com o princípio rawlsiano da diferença.

\section{AÇÕES AFIRMATIVAS NA LEGISLAÇÃO BRASILEIRA}

O ordenamento jurídico brasileiro alberga importantes tipos de ações afirmativas, como forma de vedar a discriminação negativa e de fomentar e promover a igualdade efetiva.

Com efeito, o Estado pode adotar dois instrumentos para a garantia da igualdade, nos moldes preconizados pela Constituição Federal de 1988 (CF/88), quais sejam, o instrumento repressivo e o instrumento promocional.

O instrumento repressivo, como é intuitivo, destina-se a vedar, reprimir e sancionar casos de discriminação negativa, entendida como aquela que exclui, rebaixa ou avilta o ser humano. Nesse sentido, a própria $\mathrm{CF} / 88$ estabelece que a lei punirá qualquer discriminação atentatória dos direitos fundamentais (art. 5 XLI), bem como que o racismo constitui crime inafiançável e imprescritível, sujeito a pena de reclusão, nos termos da lei (art. 5º XLII) (BRASIL, 1988). Como resultado dessa diretriz constitucional, editou-se a Lei $\mathrm{n}^{\circ}$ 7716/1989, que pune crimes resultantes de discriminação ou preconceito de raça, cor, etnia, religião ou procedência nacional (BRASIL, 1989).

Em que pese a relevância dos instrumentos repressivos, eles não revelam suficientes para a concretização da igualdade material.

Por tal motivo, deve o Estado valer-se também dos instrumentos promocionais, consubstanciados na adoção de políticas compensatórias, ou seja, ações afirmativas, para que a igualdade real seja alcançada com maior brevidade.

Sobre a variedade possível, André de Carvalhos Ramos observa que:

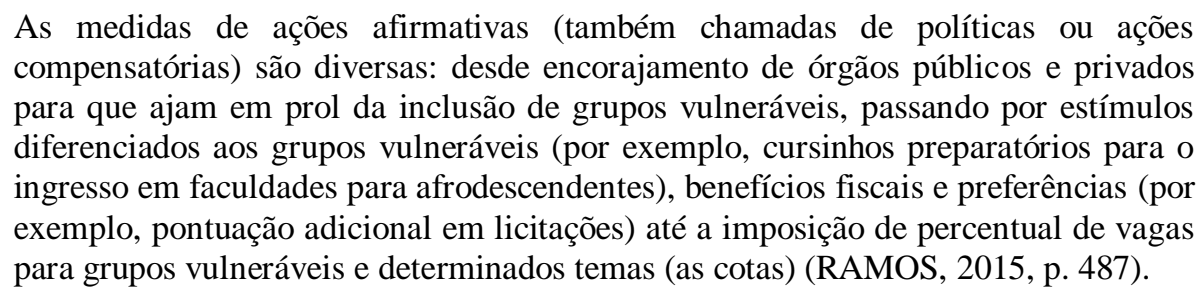


$\mathrm{Na}$ legislação brasileira, é possível verificar os seguintes exemplos de ações afirmativas:

\section{I - Ações afirmativas promocionais:}

a) Reserva de vagas em empresas com 100 ou mais empregados, em favor de pessoas com deficiência ou beneficiários reabilitados da Previdência Social, em percentual que varia de $2 \%$ a $5 \%$, de acordo com o artigo 93, da Lei 8.213/1991 ${ }^{5}$ (BRASIL, 1991).

b) Cota de candidaturas em eleições (30\% no mínimo e $70 \%$ no máximo, para cada sexo), de acordo com o artigo $10, \S 3^{\circ}$, da Lei $n^{\circ} 9.504 / 1997^{6}$, com alteração introduzida pela Lei n ${ }^{\circ} 12.034 / 2009$, o que acaba por beneficiar a participação feminina na política (BRASIL, 1997).

c) Artigo 39 ${ }_{3}$ caput, da Lei $\mathrm{n}^{\mathrm{o}} 10.741 / 2003$ (Estatuto do Idoso), que assegura a gratuidade dos transportes coletivos urbanos e semi-urbanos em favor dos maiores de 65 anos de idade, bem como o $\$ 2^{\circ}$ do referido artigo, que estabelece a reserva de $10 \%$ dos assentos em favor dos idosos, nos referidos veículos (BRASIL, 2003) ${ }^{7}$.

5 Lei n” 8.213/1991: “Art. 93. A empresa com 100 (cem) ou mais empregados está obrigada a preencher de $2 \%$ (dois por cento) a $5 \%$ (cinco por cento) dos seus cargos com beneficiários reabilitados ou pessoas portadoras de deficiência, habilitadas, na seguinte proporção:

I - até 200 empregados...............................................................................2\%;

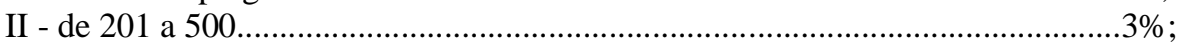

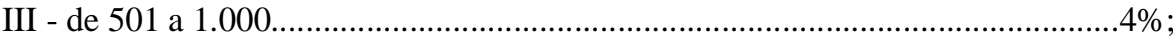

IV - de 1.001 em diante. .................................................................................5\%".

${ }^{6}$ Lei no 9.504/1997: “Art. 10. Cada partido ou coligação poderá registrar candidatos para a Câmara dos Deputados, a Câmara Legislativa, as Assembleias Legislativas e as Câmaras Municipais no total de até 150\% (cento e cinquenta por cento) do número de lugares a preencher, salvo:

I - nas unidades da Federação em que o número de lugares a preencher para a Câmara dos Deputados não exceder a doze, nas quais cada partido ou coligação poderá registrar candidatos a Deputado Federal e a Deputado Estadual ou Distrital no total de até $200 \%$ (duzentos por cento) das respectivas vagas;

II - nos Municípios de até cem mil eleitores, nos quais cada coligação poderá registrar candidatos no total de até $200 \%$ (duzentos por cento) do número de lugares a preencher.

$\S 1^{\circ}$ (Revogado).

$\S 2^{-}$(Revogado).

$\S 3^{\mathrm{o}}$ Do número de vagas resultante das regras previstas neste artigo, cada partido ou coligação preencherá o mínimo de $30 \%$ (trinta por cento) e o máximo de $70 \%$ (setenta por cento) para candidaturas de cada sexo”.

7 Lei 10.741/2003: “Art. 39. Aos maiores de 65 (sessenta e cinco) anos fica assegurada a gratuidade dos transportes coletivos públicos urbanos e semi-urbanos, exceto nos serviços seletivos e especiais, quando prestados paralelamente aos serviços regulares.

$\S 1^{\mathrm{o}}$ Para ter acesso à gratuidade, basta que o idoso apresente qualquer documento pessoal que faça prova de sua idade. 


\section{DIREITOS HUMANOS E AÇÕES AFIRMATIVAS NO DIREITO BRASILEIRO: CONTRIBUIÇÃO DA TEORIA LIBERAL DE JOHN RAWLS}

d) O Programa Universidades para Todos (ProUni), regido pela Lei $n^{\circ}$ 11.096/2005, destinado à concessão de bolsas de estudo integrais e bolsas de estudo parciais de 50\% (cinquenta por cento) ou de $25 \%$ (vinte e cinco por cento) para estudantes de cursos de graduação e sequenciais de formação específica, em instituições privadas de ensino superior, com ou sem fins lucrativos, prevendo bolsas para alunos carentes, assegurando cotas para alunos egressos da rede pública, da rede privada (desde que tenham cursado com bolsa integral), pessoa com deficiência e professor da rede pública, para alguns cursos (BRASIL, 2005).

Ainda no viés promocional, André de Carvalho Ramos lembra que "em 2012, o STF reconheceu a constitucionalidade da adoção de cotas para afrodescendentes em universidades, ao julgar improcedente a ADPF 186 (Relator Min. Ricardo Lewandowski)" (RAMOS, 2015, p. 488).

Em sede constitucional, André de Carvalho Ramos traz a seguinte síntese de exemplos de diferenciações com natureza positiva, consistentes:

\footnotetext{
i) no tratamento previdenciário privilegiado às mulheres (art. $40, \S 1^{\circ}$, III, e art. 201 , $\left.\S 7^{\circ}, \mathrm{I}\right)$;

ii) na isenção das mulheres e eclesiásticos do serviço militar obrigatório em tempo de paz, sujeitos, porém, a outros encargos que a lei lhes atribuir (art. 143, §2 $2^{\circ}$;

iii) na garantia de um salário mínimo de benefício mensal à pessoa com deficiência e ao idoso que comprovem não possuir meios de prover à própria manutenção ou de tê-la provida por sua família, conforme dispuser a lei (art. 203, V);

iv) na previsão de que a lei disporá sobre a fixação de datas comemorativas de alta significação para os diferentes segmentos étnicos nacionais (art. 215, §2 $2^{\circ}$ ), entre outras (RAMOS, 2015, p. 484).
}

\section{II - Ações afirmativa repressivas:}

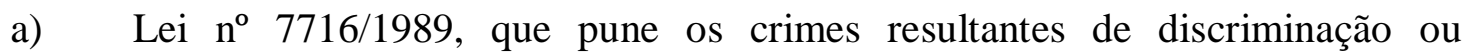
preconceito de raça, cor, etnia, religião ou procedência nacional (BRASIL, 1989).

b) Artigo $8^{\circ}$, da Lei 7.853/1989, que tipifica como crime, punível com reclusão de 2 a 5 anos e multa, condutas discriminatórias contra pessoas com deficiência, tais como: I recusar, cobrar valores adicionais, suspender, procrastinar, cancelar ou fazer cessar inscrição de aluno em estabelecimento de ensino de qualquer curso ou grau, público ou privado, em razão de sua deficiência; II - obstar inscrição em concurso público ou acesso de alguém a

$\S 2^{\mathrm{o}}$ Nos veículos de transporte coletivo de que trata este artigo, serão reservados $10 \%$ (dez por cento) dos assentos para os idosos, devidamente identificados com a placa de reservado preferencialmente para idosos". 
qualquer cargo ou emprego público, em razão de sua deficiência; III - negar ou obstar emprego, trabalho ou promoção à pessoa em razão de sua deficiência; e IV - recusar, retardar ou dificultar internação ou deixar de prestar assistência médico-hospitalar e ambulatorial à pessoa com deficiência (BRASIL, 1989).

c) Lei $\mathrm{n}^{\mathrm{o}}$ 11.340/2006, conhecida como Lei Maria da Penha, que cria mecanismos para coibir a violência doméstica e familiar contra a mulher.

$\mathrm{O}$ ordenamento jurídico brasileiro, assim, prevê mecanismos repressivos e promocionais de ações afirmativas, fundados em discriminações e dívidas históricas e na necessidade de aceleração da inserção de determinados grupos, considerados vulneráveis em termos de aptidão para o exercício pleno de direitos em igualdade de condições com os demais atores sociais.

\section{CONCLUSÃO}

A igualdade de todos perante a lei traduz importante conquista histórica contra os regimes totalitários e do surgimento do Estado de Direito.

Não obstante, o estudo dos direitos humanos na história demonstra que a igualdade formal, ou de todos perante a lei, não foi capaz de alterar o quadro de miserabilidade e de vulnerabilidade de considerável parte da população, mormente durante a Revolução Industrial europeia, no século XIX, o que deflagrou movimentos de reivindicação por direitos sociais, que demandavam prestações positivas por parte do Estado, por meio da oferta de bens materiais aptos à garantir o patamar mínimo existencial das pessoas.

Nesse contexto, avulta a importância das chamadas ações afirmativas, compreendidas como meios para a promoção da igualdade real entre pessoas que não se encontram no mesmo patamar e que não tiveram as mesmas oportunidades de acesso a bens, serviços e posições na sociedade, ligadas à educação, cultura, trabalho, entre outros.

Embora o pensamento liberal de John Rawls enfatize a prevalência dos direitos civis e das liberdades públicas, oferece, ademais, importante contribuição para o embasamento das ações afirmativas, mormente na formulação do princípio da diferença, no qual se admite tratamento diferenciado entre as pessoas, desde que se destine a beneficiar os menos favorecidos, ou a parte hipossuficiente na sociedade. 
A Constituição Federal de 1988 e a legislação infraconstitucional, inspiradas no valor igualdade, prevê medidas de ações afirmativas nas vertentes repressiva e promocional, como mecanismos capazes de conferir concretude à igualdade material e de garantir a oferta de oportunidade a todos, sem nenhuma distinção.

\section{REFERÊNCIAS}

ALMEIDA, Luciana Dayoub Ranieri de. Ações afirmativas e a concretização do princípio da igualdade no direito brasileiro. Belo Horizonte: Fórum, 2011.

BARCELLOS, Ana Paula de. A eficácia jurídica dos princípios constitucionais: o princípio da dignidade da pessoa humana. 3.ed. Rio de Janeiro: Renovar, 2011.

BRASIL. Lei Federal 12.034, de 29 de setembro de 2009. Altera as Leis nos 9.096, de 19 de setembro de 1995 - Lei dos Partidos Políticos, 9.504, de 30 de setembro de 1997, que estabelece normas para as eleições, e 4.737, de 15 de julho de 1965 - Código Eleitoral. Disponível em: <http://www.planalto.gov.br/ccivil_03/_ato2007-2010/2009/lei/L12034.htm> Acesso em: 09 abr.2018.

BRASIL. Lei Federal $\mathbf{n}^{\mathbf{0}}$ 11.340, de 07 de agosto de 2006. Cria mecanismos para coibir a violência doméstica e familiar contra a mulher. Disponível em:

<http://www.planalto.gov.br/ccivil_03/_ato2004-2006/2006/lei/L11340.htm> Acesso em: 09 abr.2018.

BRASIL. Lei Federal $\mathbf{n}^{\circ}$ 11.096, de 13 de janeiro de 2005. Institui o Programa Universidade para Todos - PROUNI. Disponível em: <http://www.planalto.gov.br/ccivil_03/_ato20042006/2005/lei/L11096.htm> Acesso em: 09 abr.2018.

BRASIL. Lei Federal $\mathbf{n}^{\mathbf{0}} \mathbf{1 0 . 7 4 1}$, de $\mathbf{1}^{\mathbf{0}}$ de outubro de 2003. Estatuto do Idoso. Disponível em: <http://www.planalto.gov.br/ccivil_03/leis/2003/L10.741compilado.htm> Acesso em: 09 abr.2018.

BRASIL. Lei Federal no 9.504, de 30 de setembro de 1997. Estabelece normas para as eleições. Disponível em: <http://www.planalto.gov.br/ccivil_03/leis/L9504compilado.htm> Acesso em 09 abr.2018.

BRASIL. Lei Federal $\mathbf{n}^{0}$ 8.213, de 24 de julho de 1991. Dispõe sobre os Planos de Benefícios da Previdência Social e dá outras providências. Disponível em:< http://www.planalto.gov.br/ccivil_03/leis/L8213compilado.htm> Acesso em: 09 abr.2018.

BRASIL. Lei Federal $\mathbf{n}^{\mathbf{0}} \mathbf{7 . 8 5 3}$, de 24 de outubro de 1989. Estatuto da Pessoa com Deficiência. Disponível em:

<http://www.planalto.gov.br/ccivil_03/leis/L7853compilado.htm> Acesso em: 09 abr.2018. 
BRASIL. Lei Federal $\mathbf{n}^{\mathbf{0}}$ 7.716, de 05 de janeiro de 1989. Define os crimes resultantes de preconceito de raça ou de cor. Disponível em:

<http://www.planalto.gov.br/ccivil_03/leis/L7716compilado.htm> Acesso em: 09 abr.2018.

BRASIL. Constituição da República Federativa do Brasil (1988). Disponível em:

<http://www.planalto.gov.br/ccivil_03/constituicao/ConstituicaoCompilado.htm>. Acesso em: 09 abr.2018.

BRITO FILHO, José Cláudio Monteiro de. Ações afirmativas. 2.ed. São Paulo: Ltr, 2013.

CHEVALLIER, Jacques. O estado de direito. Tradução de Antônio Araldo Ferraz Dal Pozzo e Augusto Neves Dal Pozzo. Belo Horizonte: Fórum, 2013.

DOUZINAS, Costas. O fim dos direitos humanos. Tradução de Luzia Araújo. São Leopoldo: Unisinos, 2009.

FRANÇA. Declaração dos Direitos do Homem e do Cidadão, de 26 de agosto de 1789. Disponível em: <http://www.direitoshumanos.usp.br/index.php/Documentos-anteriores$\% \mathrm{C} 3 \%$ A0-cria\%C3\% A7\%C3\% A3o-da-Sociedade-das-Na\%C3\%A7\%C3\%B5es-at\%C3\%A91919/declaracao-de-direitos-do-homem-e-do-cidadao-1789.html> Acesso em: 09 abr.2018.

GUERRA, Sidney. Curso de direitos humanos: curso elementar. 3.ed. São Paulo: Saraiva, 2015.

KANT, Immanuel. Fundamentação da metafísica dos costumes e outros escritos. Tradução: Leopoldo Holzbach. São Paulo: Martin Claret, 2011.

LENZA, Pedro. Direito constitucional esquematizado. 18.ed. São Paulo: Saraiva, 2014.

MACIEL, Álvaro dos Santos. A inclusão da pessoa com deficiência no mercado de trabalho. São Paulo: Ltr, 2011.

MORAES, Maria Celina Bodin de. Conceito de dignidade humana: substrato axiológico e conteúdo normativo. In: SARLET, Ingo Wolfgang (org.). Constituição, direitos

fundamentais e direito privado. Porto Alegre: Livraria do Advogado, 2003.

ORGANIZAÇÃO das Nações Unidas. Pacto Internacional sobre Direitos Econômicos, Sociais e Culturais, de 16 de dezembro de 1966. Disponível em:

<http://www.unfpa.org.br/Arquivos/pacto_internacional.pdf> Acesso em: 09 abr.2018.

ORGANIZAÇÃO das Nações Unidas. Pacto Internacional sobre Direitos Civis e Políticos, de 16 de dezembro de 1966. Disponível em: 〈http://www.cjf.jus.br/caju/tratados.pdf> Acesso em: 09 abr.2018.

ORGANIZAÇÃO das Nações Unidas. Declaração Universal dos Direitos Humanos, de 10 de dezembro de 1948. Disponível em: <

http://unesdoc.unesco.org/images/0013/001394/139423por.pdf> Acesso em 09 abr.2018. 
PIOVESAN, Flávia. Temas de direitos humanos. 7.ed. São Paulo: Saraiva, 2014.

PIOVESAN, Flávia. Ações afirmativas no Brasil: desafios e perspectivas. In: NOVELINO, Marcelo (org.). Leituras complementares de direito constitucional: direitos humanos e direitos fundamentais. 3.ed. Salvador: Editora Juspodivm, 2008.

RAMOS, André de Carvalho. Curso de direitos humanos. 2.ed. São Paulo: Saraiva, 2015.

RAWLS, John. Uma teoria da justiça. Tradução de Jussara Simões. Revisão técnica e da tradução: Álvaro de Vita. 3.ed. São Paulo: Martins Fontes, 2008.

SANDEL, Michael J. Justiça: o que é fazer a coisa certa. Tradução de Heloísa Matias e Maria Alice Máximo. 22.ed. Rio de Janeiro: Civilização Brasileira, 2016.

SARLET, Ingo Wolfgang. Dignidade da pessoa humana e direitos fundamentais. Porto Alegre: Livraria do Advogado, 2001.

SENA, Max Emiliano da Silva. O trabalho digno como meio de inclusão social no ordenamento jurídico brasileiro. In: XXV CONGRESSO NACIONAL DO CONPEDI CURITIBA, Curitiba, PR: 2016, p. 57-76. Disponível em:

< https://www.conpedi.org.br/publicacoes/02q8agmu/zwub6y85/f8C4j78b9mY3cgvo.pdf >. Acesso em: 09 abr.2018. 